Article

\title{
Are Lions Green?: Child L2 Learners' Interpretation of English Generics and Definite Determiners
}

\author{
Alexandra Morales-Reyes ${ }^{1, *}$ and Begoña Arechabaleta-Regulez ${ }^{2}$ \\ 1 Department of Hispanic Studies, University of Puerto Rico at Mayagüez, Mayagüez PR 00681, Puerto Rico \\ 2 Department of Spanish \& Portuguese, University of Illinois at Urbana-Champaign, 707 S. Mathews Ave., \\ Urbana, IL 61801, USA; arechab2@illinois.edu \\ * Correspondence: alexandra.morales10@upr.edu; Tel.: +1-787-633-6211
}

Academic Editor: Maria del Carmen Parafita Couto, Usha Lakshmanan and Osmer Balam Received: 15 July 2017; Accepted: 25 October 2017; Published: 31 October 2017

\begin{abstract}
The aim of this small-scale study (22 participants) was to analyze how L1-Spanish L2-English children interpret English noun phrases (NPs) by taking into consideration two variables: children's age and amount of input. These two variables were studied in relation to children's developmental tendencies and language transfer. Children begin with an innate predisposition for the generic interpretation, which leads them to incorrectly interpret some specific NPs. In contrast, transfer from the L1 explains the incorrect mapping between NP and interpretation in adult L2 speakers. We examined 22 L1-Spanish L2-English children and a control group of L1-English children on their interpretation of English NPs through an online task. Results revealed that L2 children's interpretations significantly differ from the interpretations of the control group. We propose that like L1 children, child L2 learners will have to overcome their natural predisposition to interpret NPs as generic. However, child L2 learners must also overcome transfer effects from their L1. Additionally, results seem to suggest that the amount of input plays a role in learners' interpretations. We propose that children who receive similar amounts of input in their two languages become aware of the differences faster, particularly in the forms where there is no overlapping between the languages (i.e., bare NPs).
\end{abstract}

Keywords: child L2 acquisition; noun phrases; generic; transfer

\section{Introduction}

Interpreting the noun phrase (NP) the birds in a sentence such as The birds sing in the morning may not seem like a difficult task for an English adult native speaker. If asked whether the noun phrase refers to birds as a kind (i.e., generic meaning) or just a subset of birds that like singing in the morning (i.e., specific meaning), without much hesitation, adult native speakers will say that in that sentence birds refers to a subset of birds that like singing in the morning. Although at first sight, distinguishing the meaning of a NP might not seem like a complicated task, acquiring the meaning of plural NPs is not as straightforward as one might initially think. To correctly interpret a NP, not only does the speaker need to learn the morphosyntactic cues (e.g., determinants) but also their semantics (e.g., specific vs. generic). In this study, we focused on how 22 L1-Spanish L2-English children interpret English definite plural and bare plural NPs.

Specific and generic plural NPs are an interesting case to consider in both Spanish and English because the two languages differ in the way they express genericity. In English, genericity in plural NPs is expressed through a bare plural (e.g., Birds sing). However, Spanish, at least in canonical argument positions, does not allow bare NPs. Bare NPs can only be used in predicative NPs. In Spanish, genericity is expressed through definite plural NPs (e.g., The birds), but definitive plural NPs can also express specificity in Spanish (see Table 1). 
Table 1. Noun phrase (NP) types and mapping of generic and specific in Spanish and English.

\begin{tabular}{ccc}
\hline & Generic & Specific \\
\hline Spanish & Los elefantes comen maní & Los elefantes comen maní \\
English & Elephants eat peanuts & The elephants eat peanuts \\
\hline
\end{tabular}

Because both languages, Spanish and English, have the syntactic possibility of expressing bare plurals and definite plurals but differ in the mapping of potential semantic interpretations of these forms, it is of particular interest to investigate the remapping between meaning and syntactic structure from the L1 to the L2. To date, there have been few studies that have looked at the acquisition of generecity by child L2 learners [1,2]. Therefore, the present study aims to contribute to this area of research by examining the interpretation of English generic and non-generic NPs in L1-Spanish children. Moreover, we conducted our analysis by taking into consideration two variables: children's age and amount of input they receive in Spanish and in English. However, as this was a small-scale study involving only 22 child participants, our findings are suggestive rather than definitive. Future studies should consider testing a larger sample size to validate our findings.

\subsection{Linguistic Theoretical Background of Subject Nominals in Spanish and in English}

In order to better understand the form-meaning differences of nominals across languages, we adopted Chierchia's Nominal Mapping Parameter (NMP) [3]. The NMP offers a theoretical account of the observed cross-linguistic differences between English and Spanish in the distribution of NPs and their interpretations. According to Chierchia, languages can be classified according to their flexibility in allowing bare nouns in argument positions. The parameter divides language into three groups as illustrated in (1).

1. Nominal Mapping Parameter

NP [+arg -pred], e.g., Classifier languages like Chinese

NP [-arg +pred] e.g., Romance languages like Spanish

NP [+arg +pred]. e.g., Germanic languages like English

What this means is that in languages without determiners, such as Chinese, NPs are argumentative and can then occur bare in argument position. However, in languages such as Spanish, NPs can only behave as predicates. They require a determiner to be turned into arguments. Finally, in languages such as English, NPs can either behave as arguments (they can occur bare) or as predicates (they need a determiner). Thus, these languages are the 'union' of the previous two. However, there exists cross-linguistic variation within the groups. For example, some Romance languages (e.g., Spanish), allow bare NPs in a lexically governed position like in (2).

$\begin{array}{lll}\text { 2. } & \text { Necesito } \quad \text { lápices } & \text { para mi clase de arte } \\ \text { Need } & \text { pencil-PL } & \text { for my class of art } \\ \text { 'I need pencils for my art class.' } & \end{array}$

For this study, we wanted to compare a [-arg +pred] language (Spanish) to a [+arg +pred] language (English). Unlike in Spanish, bare plural arguments in English are allowed in any syntactic position, and they appear in generic sentences. However, they typically do not take a specific reading. In Spanish, definite plurals can be interpreted as generic or specific. However, in English, definite plurals can only have a specific interpretation. The remaining question then is: why can English not use definite plurals for the same purpose? Chierchia [3] argues that a principle of economy, what he calls the "Avoid Structure Principle", will force choosing generic bare plurals over generic definite plurals in English. According to this principle, when a bare nominal and a determiner + nominal can have the same meaning, the simple structure will be chosen. In English, the generic reading of definite plurals is blocked by the bare plurals. However, in Spanish, the absence of the bare plurals allows the definite plurals to include both the generic and the definite reading. 
This economy principle is also applicable for the acquisition of the correct interpretation of bare plurals and definite plurals [4]. Children start out with the assumption that all NPs have a generic meaning, since it is the default, while definiteness is absent in child grammar at the beginning. Children require greater exposure to the language to distinguish between generic and specific NPs. Section 1.3 explains in greater detail how children arrive at a target-like interpretation of the bare plural and definite plurals of their language.

\subsection{L1 Acquisition of Bare Plurals and Definite Plurals}

The ability to learn the meaning of NPs, despite the lack of linguistic transparency, has been linked to an inherent preference for the generic meaning [4]. At first, children have a predisposition towards the generic interpretation [5-8] regardless of their L1. Thus, among the possible interpretations, NPs receive a generic interpretation by default.

It has been suggested that generalizing skills develop as an innate cognitive disposition, regardless of the language being acquired. This explains why even with the lack of a form intended exclusively to express genericity, generics are acquired by children at a very early age and even earlier than other quantifiers (e.g., all, some) [9-11]. In addition, some consider that generics are basic representations at the cognitive level [12] and that they are processed more quickly [13].

However, this does not mean that children are not able to distinguish between generic and specific. Children at the young age of two years and eight months $(2 ; 8)$ old are able to distinguish between generic and specific [6]. However, interpreting NPs remains a challenging task for children even after the preschool years [6,8]. Children's bias for the generic interpretation leads them to misinterpret some specific NPs. In both Spanish and English, 6-year-old children still tend to show non-target responses. For example, Spanish speaking children sometimes interpret the demonstrative determiner (e.g., Estos elefantes comen maní 'These elephants eat peanuts') as generic. English speaking children, on the other hand, tend to extend the generic interpretation to definite NPs. However, the proportion of non-target responses (e.g., generic responses to English definite NPs) may be influenced by the task used in the study.

For example, in Pérez-Leroux et al. [8], children incorrectly interpreted English definite NPs 70\% of the time, while Gelman and Raman reported a much lower rate of incorrect responses, $15 \%$ of the time [6]. These contrasting results could be attributed to a task effect. The task in Perez-Leroux et al. favored the generic interpretation over the specific one. In their test, the questions were preceded by a short story where the characters (animals with atypical characteristics) were introduced with a definite determinant (e.g., Freddie the Tiger and Papo the Tiger are vegetarians). After introducing the characters with a definite NP, pragmatically, it would be odd to refer to them again as "the tigers" which may have instead led the children to interpret questions such as Do the tigers eat meat? as referring to the species and not to the specific tigers that had already been introduced in the story $[14,15]$. On the contrary, in the Gelman and Raman task, there was no story introducing the questions. Instead, children saw an image (e.g., two penguins) and were asked either a generic (e.g., do birds fly?) or a specific question (e.g., do the birds fly?). Thus, it could be argued that the specific interpretation was more salient than the generic one. However, assuming that the task had a bias towards the specific interpretation, then it is revealing that the children still incorrectly interpreted definite NPs as generic, especially considering that English-speaking children are much more successful with the plural bare NPs and rarely opt to interpret them as specific $[6,8]$.

\subsection{Acquisition of Bare Plurals and Definite Plurals by Bilinguals}

Let us now turn to bilingual acquisition, where the children learn two languages simultaneously and may be affected not only by developmental effects (generic default), but also by cross-linguistic influence. Serratrice et al. studied the interpretation of plural NPs in two groups of bilinguals: Spanish-Italian and English-Italian bilingual children. Children were classified into two age groups: the younger children (6-7 years old) and the older children (8-10 years old). Spanish and Italian 
are typologically similar whereas in English, the mapping between form and meaning works differently. Thus, we would expect Spanish-Italian bilinguals to perform similar to Italian monolinguals. However, if cross-linguistic transfer plays a role in bilingual children, we would expect English-Italian bilinguals to diverge from the monolingual norm in their interpretations of Italian or English NPs due to an overlapping in how the two languages express genericity and specificity in the NP.

Serratrice et al. found evidence for cross-linguistic transfer in bilingual children [14]. English-Italian children were less accurate at judging the grammaticality of Italian NPs than the Spanish-Italian group, whose performance was not significantly different from that of the Italian group. Like the Italian monolinguals, the Spanish-Italian bilinguals accepted definite NPs in both generic and specific contexts. In addition, both groups categorically rejected bare plural NPs. However, although the English-Italian bilinguals were able to accept definite NPs in generic contexts, they failed to consistently reject ungrammatical bare plural NPs in both generic and specific contexts.

Nonetheless, when the English-Italian bilinguals were tested in English and compared to English monolinguals, the responses of both groups on the grammaticality judgment task did not differ significantly. The English-Italian bilinguals were not more likely than the English monolinguals to judge English definite NPs as grammatical in the generic context. Also, similar to the English monolinguals, they accepted bare plural NPs in generic contexts. According to Serratrice et al. [14]., these findings support a unilateral cross-linguistic influence: Linguistic influence occurs from English to Italian but not from Italian to English. Following Chierchia's NMP proposal [4], the authors explained that in bilingual children, cross-linguistic influence will occur from the language with the most economical NMP setting. English could be argued to be more economical because, in contrast with Italian, it does not require a projection of a determiner (definite determiner) to turn NPs into arguments.

Serratrice et al. also investigated how the amount of input affected the bilinguals' performance [14]. They found that the English-Italian bilinguals who were living in a mostly English environment (i.e., England) were more likely to show cross-linguistic influence than those who were living in a mostly Italian environment (i.e., Italy). Evidence that variations in the input play a role in the interpretation of NPs has also been reported for Spanish heritage speakers [16,17]. Heritage speakers tend to exhibit transfer from their dominant language (e.g., English) to their heritage language (e.g., Spanish). For instance, they allow bare plural NPs in Spanish and are more likely to interpret definite NPs as specific, whereas native speakers opt more for the generic interpretation.

Interpretation of English determiners is also very challenging for adult L2 learners. As with bilingual and heritage speakers, L2 learners are affected by transfer. L1-Spanish L2-English adults are overly influenced by the L1 in their interpretations of English NPs [15,16]. Ionin et al. examined the interpretation of English NPs in a group of Spanish speaking adults [15]. The results revealed that learners tended to interpret definite NPs as generic, particularly beginning-level learners who frequently opt for the generic interpretation (e.g., $80 \%$ of the time). Adult L2 learners also appeared to be more successful with bare plural NPs than with definite plural NPs. Although they sometimes incorrectly interpreted bare NPs as specific, they tended to favor the generic interpretation.

Child L2 learners also appear to favor the generic interpretation. However, they seem to be less affected by their L1 than adult L2 learners. Knob suggested that L2 children are not as affected by their L1 as expected [1]. In order to test cross-linguistic influence and the effect of length of exposure to the L2, Knob tested 51 English-speaking children learning French or German as a L2 with different amounts of L2 exposure (low, mid and high). While genericity is expressed by bare nouns in English and German, French generic reference is usually expressed by plural definite articles. Similar to other Romance languages (e.g., Spanish), French definite plural articles can also have a non-generic interpretation. Participants completed a Truth Value Judgment Task (TVJT) for which they listened to a story and judged the truthfulness of statements produced by a puppet in reference to the preceding short story. The puppet always produced a definite plural sentence (e.g., The sharks are dangerous). Taking into account that adult L2 learners have consistently reported to be affected by L1 transfer, 
Knob expected L2 children, particularly those with a low amount of L2 exposure to show transfer from their L1 (i.e., English) by displaying a clear preference for the non-generic interpretation. However, the non-generic preference was not as strong as expected because children accepted definite plurals as generic even though English does not allow it. While length of exposure to the L2 was not a significant effect, there was a positive correlation between a generic interpretation and length of exposure to French. These results suggest that children were learning that, unlike English, French plural definite NPs can have both a generic and a non-generic interpretation. However, children with a high exposure to German also opted for the generic interpretation. Children in this group were expected to give non-generic interpretation because generic reference in German, like in English, is ungrammatical with definite NPs. Thus, results suggested an overall generic preference by children regardless of whether their L1 and/or L2 accepts that generic reading.

To summarize, previous studies have showed that the acquisition of genericity is overall a complicated task. Transfer from the dominant language usually explains the incorrect mapping between NP and interpretation in L2 speakers. However, transfer from the dominant language to the less dominant language appears to be stronger between adult L2 learners than between child L2 learners. Due to their age, L2 child learners are not only affected by their L1 but also by developmental strategies that usually let them favor the generic interpretation.

Against this backdrop, we addressed the following research questions:

1. Are Spanish speaking children affected by transfer in their interpretation of English NPs?

2. Does age influence Spanish speaking children's interpretation of English plural NPs?

3. Does input variability influence Spanish speaking children's interpretation of English plural NPs?

The following hypotheses were formulated:

1. We predict that if child L2 acquisition resembles bilingual acquisition and if as proposed by Serratrice et al. cross-linguistic influence is unilateral, (i.e., influence only occurs from the language with the most economical construction), interpretation of English NPs in Spanish-speaking children will not be influenced by the Spanish NMP setting [14]. Thus, they will not perform significantly different from English native speakers in the definite condition and will also opt for the generic condition in the bare plural condition. However, if acquisition of NP interpretations in child L2 learners more closely resembles adult L2 acquisition, we expect children to show transfer from their L1 (i.e., Spanish). They will then perform significantly different from native speakers, and they will tend to overextend the generic interpretation to definite NPs. In addition, if as proposed by Ionin et al. [15], L2 learners are able to dissociate syntax and semantic knowledge and if it is easier for them to learn that bare plural NPs are allowed in English than to unlearn that definite NPs can have a generic meaning, we would expect child L2 learners to perform better on the bare plural NPs than on the definite NPs.

2. Children have a natural predisposition for the generic interpretation, particularly very young children. Thus, we expect the younger child L2 learners to favor the generic interpretation more than the older child L2 learners.

3. Input variations have been reported to affect learners' NP interpretations. Interpretations of NPs are influenced by the language to which the learner is more frequently exposed. We predict that child L2 learners who are more frequently exposed to English will be more successful at interpreting English NPs.

\section{Materials and Methods}

\subsection{Participants}

A group of 22 L2 English-speaking children participated in the study. All the parents provided consent for their children to participate in the study. The children were native speakers of Spanish and 
were all living in Puerto Rico at the time of the testing. They were divided into two groups according to their age: 12 children in the younger group (4;11 to 7;11 years old) and 10 children in the older group (8;4 to $11 ; 7$ years old). They had between 1 to 8 years of exposure to Spanish. They were formerly exposed to English around the age of 3.5 or 5 years old. It is worth mentioning that because of the political relationship between the island of Puerto Rico and the United States, both English and Spanish are official languages on the island. However, most families in Puerto Rico speak Spanish at home $(95 \%$ according to Census 2010). English language presence is mostly through the media. Many families have cable TV. Therefore, children may be exposed to English through TV programs, video games, and movies. In most schools, English is taught as a foreign language course (e.g., 50-min class 5 days per week). However, there are also schools with total or partial immersion programs. Because children were formally exposed to English at school, age and time of exposure are confounded variables: the younger the children, the less exposure they have had to English and vice versa: the older the children, the greater exposure they have had to English. We also collected data on the amount of input that children were receiving in Spanish and English. In order to collect this data, we asked parents to report the percentage of time their child spends reading and watching TV in Spanish and in English. We also asked children how frequently they used Spanish and English at home with their family and at school with their friends. Children responded through a 5 point-Likert scale. See examples in (3a) and (3b). These questions are part of a larger questionnaire about Puerto Rican children's language attitude and use. The questionnaire was in Spanish and was administered orally by one of the researchers.

3. ¿Cuánto usas el español con tu familia?

'How much do you use Spanish with your family?'

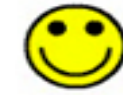

Muchísimo

'A lot.'
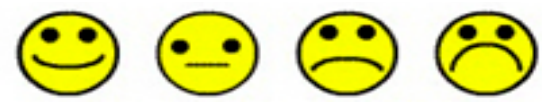

Nada

'Nothing.'

b. ¿Cuánto usas el inglés con tus amigos?

'How much do you use English with your friends?'
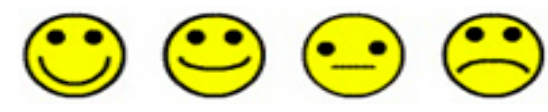

Muchísimo

'A lot.'

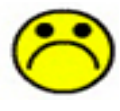

Nada

'Nothing.'

We combined these measurements (i.e., parents and children's reports) and divided the children into three categories: mainly exposed to English $(n=6)$, mainly exposed to Spanish $(n=9)$ and balanced exposure to English and Spanish $(n=7)$.

We also included a group of 16 English native speakers $(n=16)$. The English speakers were living in a state in the Midwest of United States at the time of the testing. They were between 8;1 and 11 years old.

\subsection{Instrument and Procedures}

The participants' interpretations of definite and bare plural NPs were tested through an online task designed in E-prime 2.0 (Psychology Software Tools, Sharpsburg, PA, USA). We decided to use an online design because they are usually more successful at tapping into the learner's implicit knowledge as they collect learners' automatic responses [18]. Children sat in front of a laptop and saw pairs of pictures of objects/animals with atypical characteristics (e.g., green lions). Each set of pictures was 
accompanied by pre-recorded stimuli. The recordings were made by a native English female speaker. The stimulus was either a question with a definite plural NP (e.g., Are the lions green?) or a question with bare plural NP (e.g., Are lions green?). See an example in Figure 1 (see Appendix A for a full list of sentences and images). Participants were instructed to press the "Yes" or "No" button on the computer keyboard as soon as they knew the answer to the question they heard. For the analysis, the proportion of generic and specific interpretations given by the participants was evaluated. In an item such as Figure 1, participants' responses would be analyzed as follows: Definite NP (Are the lions green?): Yes = specific interpretation, No = generic interpretation; Bare NP (Are lions green?): Yes $=$ specific interpretation, $\mathrm{No}=$ generic interpretation .

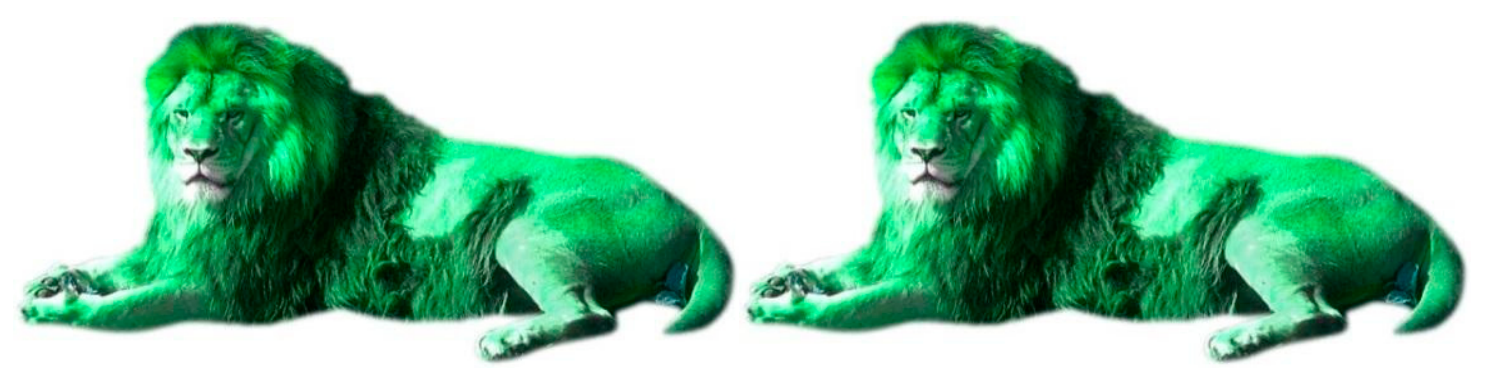

Figure 1. Task sample, picture and stimuli (definite plural noun phrase (NP)_Are the lions green? bare $\mathrm{NP}-$ Are lions green?)

The definite and the bare plural conditions were not presented together. They were presented in two different tasks at different times. Each task had four practice trials followed by the experimental section which included 10 trials. All items were presented in a randomized order.

\subsection{Results}

The $\mathrm{L} 2$ learners correctly gave a generic interpretation to $55 \%(\mathrm{SD}=3.6)$ of the bare plural NPs; however, they incorrectly gave a generic interpretation to $42.7 \%(\mathrm{SD}=0.30)$ of the definite NPs (see Figure 2). These results suggest that it was problematic for the child L2 learners to distinguish between English generics and those that were specific. However, the native speakers also displayed difficulties, particularly with interpreting the definite NPs. They extended the generic meaning to $32 \%$ $(\mathrm{SD}=0.46)$ of the definite NPs while only overgeneralizing the specific interpretation to $9 \%(\mathrm{SD}=0.28)$ of the bare NPs. That is, native speakers can distinguish that bare NPs are generic but still have difficulties interpreting the meaning of definite NPs. A Mann-Whitney test revealed that the groups were significantly different in both conditions: the definite NP $(U=95.5, p=0.016, r=-0.51)$ and the bare plural NP $(U=64.5, p=0.000, r=-0.74)$.

Studies of L1 acquisition have reported that children's age plays a role in the interpretation of NPs: The older the children, the less frequently they will extend the generic interpretation to definite NPs. In order to evaluate whether, as in L1 acquisition, child L2 learners are less likely to interpret definite NPs as generic the older they get, we divided child L2 learners into two age groups: $4 ; 11-7 ; 11$ and 8;4-11;7. Surprisingly, results revealed that the younger group was more target-like with the definite NPs, opting more frequently for the specific interpretation (65\%) than the older group (48\%). However, the older children were more successful at interpreting the bare NPs than the younger children. The generic responses of the younger group were below chance level (46.6\%), whereas the older group correctly interpreted $66 \%$ of the bare plural NPs (see Figure 3). However, a Mann-Whitney test revealed that there were no significant differences between the two age groups in the bare plural $(U=38.5, p=0.151, r=-0.30)$ or the definite condition $(U=41.5, p=0.219, r=-0.26)$. 


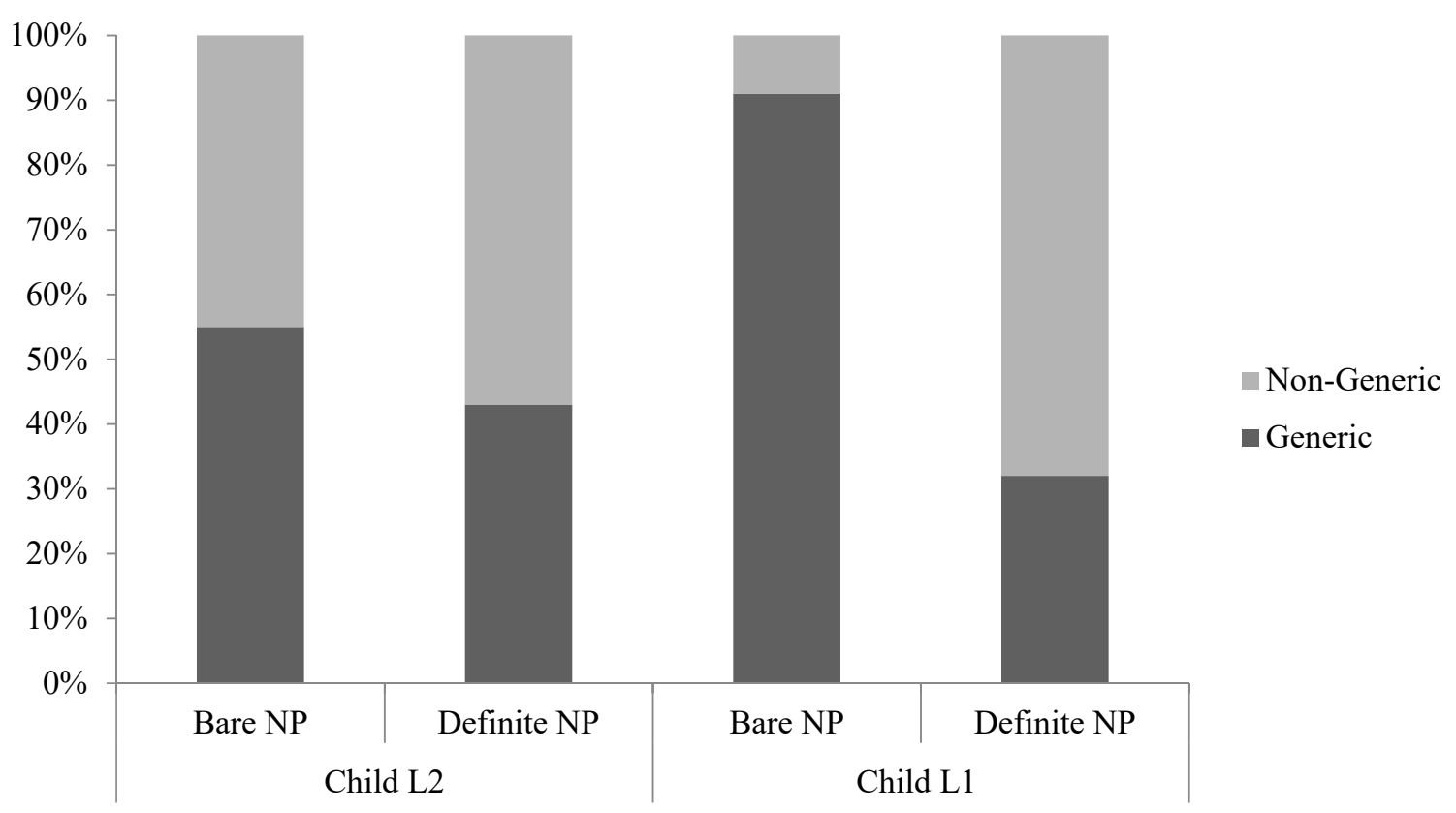

Figure 2. Interpretation of bare NPs and definite NPs by L2 and L1 children.

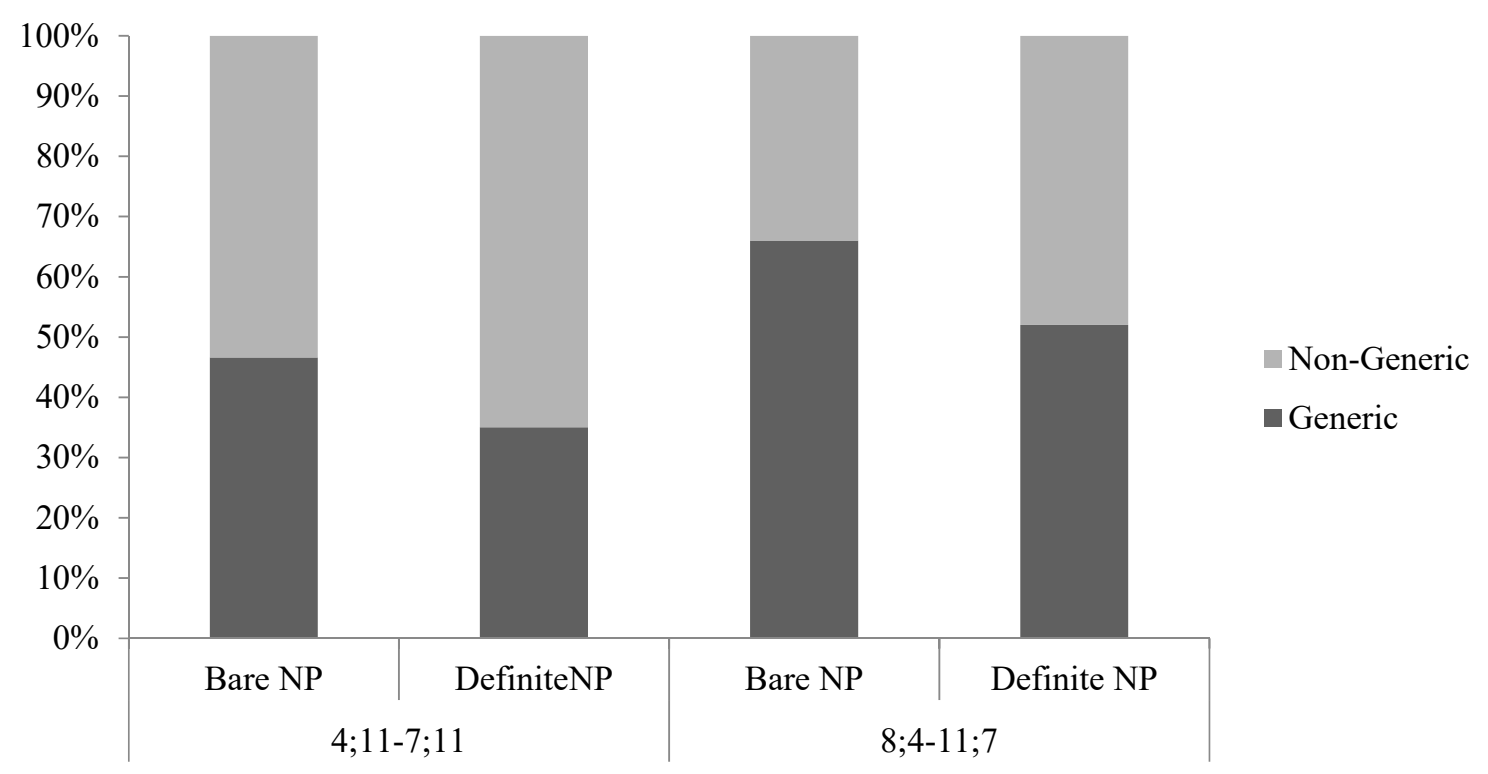

Figure 3. Interpretation of definite and bare plural NPs, according to the learner's age.

Let us turn now to the role played by the amount of input in the interpretation of bare NPs (see Figure 4). The results for the amount of input include both the younger group and the older children. The children in the balanced group showed better command as they interpreted $76 \%$ of the bare NPs as generic. The children mainly exposed to English followed the balanced group with $60 \%$ of generic responses, whereas the children who are mainly exposed to Spanish were the less accurate, only interpreting $45 \%$ of the bare NPs as generic. Nonetheless, in a Kruskal-Wallis test, the differences among the groups failed to be significant $\left(\chi^{2}(2, N=22)=1.56, p=0.89\right)$. 


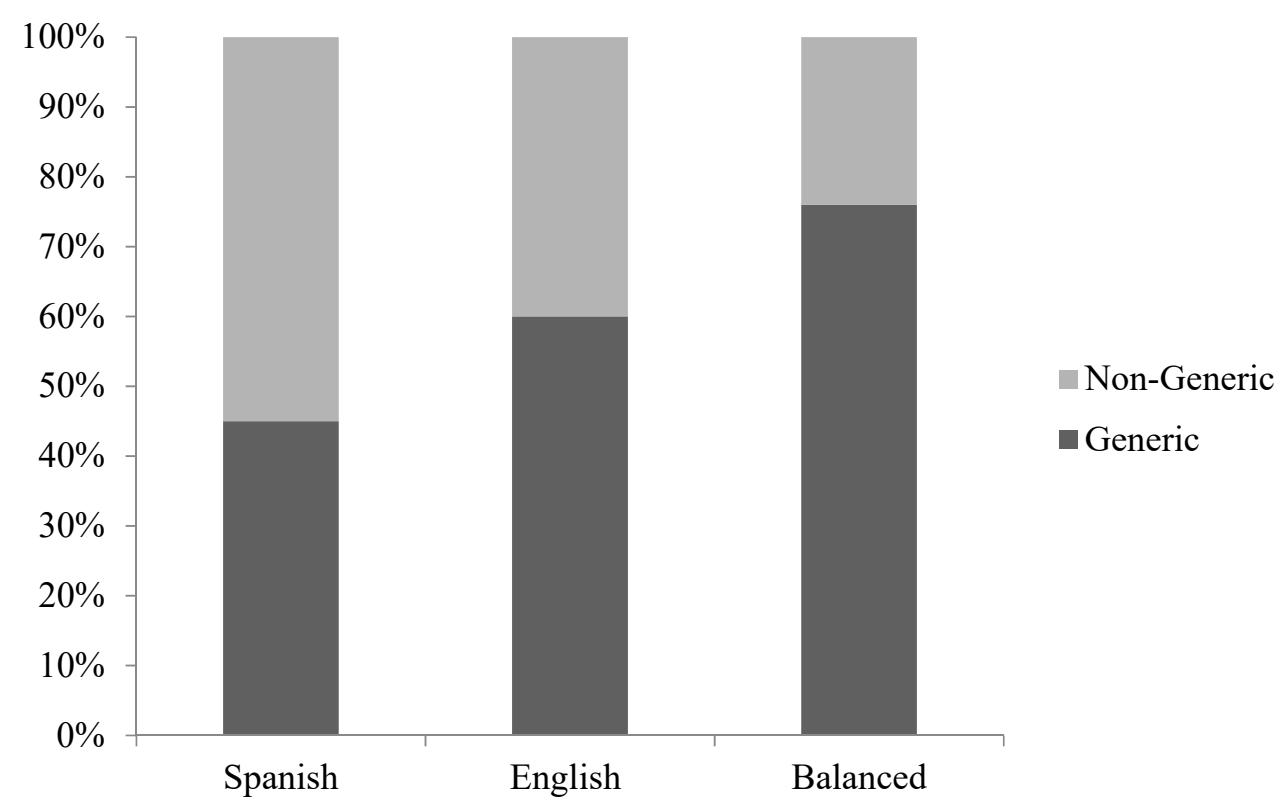

Figure 4. Interpretation of bare NPs, according to the amount of input.

In contrast to the bare NPs, performance with the definite NPs was similar across all three groups. They all displayed high percentages of overextension of the generic interpretation: Spanish (43\%), English (44\%) and balanced (45\%) (see Figure 5). As expected by the similarities in scores, no significant differences were found $\left(\chi^{2}(2, N=22)=0.220, p=0.457\right)$.

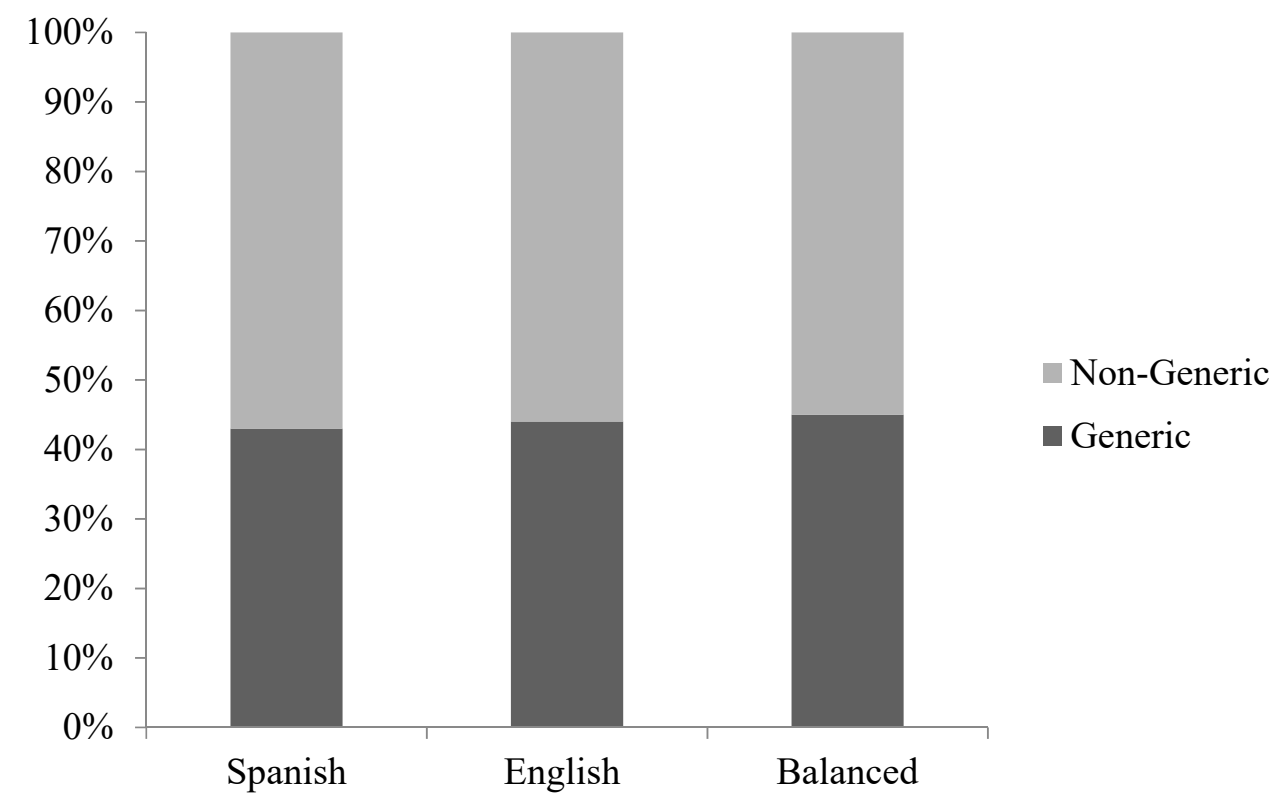

Figure 5. Interpretation of bare NPs, according to the amount of input.

To summarize, the overall results suggest that learners' performance across conditions was comparable. Overextension of the specific interpretation to bare NPs and overextension of generic interpretation to definite NPs was very similar. The findings also suggest that neither age nor amount of exposure play a significant role in NPs interpretation in child L2 learners. However, the results revealed interesting and unexpected patterns. The younger children were more prone to offer specific responses than the older children. As for the amount of input, the results seem to indicate that children 
with a balanced amount of input from the languages tend to perform better than those mainly exposed to the L2 and much better than learners who are more frequently exposed to the L1. However, it is important to note that the differences did not reach statistical significance. In the following section, we examine whether these patterns are also observed at the individual level.

\subsection{Individual Results}

We conducted an individual subject analysis for both definite and bare plural NPs, grouping children into three different patterns: generic, specific, and at chance, as described below:

(a) The generic pattern: NPs interpreted as generic $60 \%$ of the time or more

(b) The specific pattern: NPs interpreted as specific $60 \%$ of the time or more

(c) At chance pattern: half of the NPs interpreted as generic and half interpreted as specific

Overall, most learners showed the specific pattern for the definite NPs: out of the 22 learners, $12(54 \%)$ displayed a specific pattern while $8(36 \%)$ showed the generic pattern. Two learners showed no preference, performing at chance. As for the bare NPs, out of the 22 learners, $12(54 \%)$ exhibited the generic pattern whereas $9(41 \%)$ displayed the specific pattern. Just one learner performed at chance level, showing equal preference for the generic and specific pattern. We also carried out an individual subject analysis for the variables age and amount of input.

In the younger group, most children favored the specific pattern in the definite condition. They were more likely to show the specific pattern in the definite contexts than the older children who more frequently favored the generic pattern (see Table 2).

Table 2. Definite NPs: Individual subject patterns by age.

\begin{tabular}{cccccccc}
\hline Groups by Age & $N$ & Generic & Pattern $\%$ & Specific & Pattern $\%$ & At Chance & Pattern $\%$ \\
\hline $4 ; 11-7 ; 11$ & 12 & 3 & $25 \%$ & 8 & $67 \%$ & 1 & $8 \%$ \\
$8 ; 4-11 ; 7$ & 10 & 5 & $50 \%$ & 4 & $40 \%$ & 1 & $10 \%$ \\
\hline
\end{tabular}

In the bare NPs, a contrasting pattern was observed: Most children in the older group favored the generic pattern, whereas most children in the younger group exhibited the specific pattern (see Table 3).

Table 3. Bare NPs: Individual subject patterns.

\begin{tabular}{cccccccc}
\hline Groups by Age & $N$ & Generic & Pattern (\%) & Specific & Pattern (\%) & At Chance & Pattern (\%) \\
\hline $4 ; 11-7 ; 11$ & 12 & 5 & 42 & 7 & 58 & - & - \\
$8 ; 4-11 ; 7$ & 10 & 7 & 70 & 2 & 20 & 1 & 10 \\
\hline
\end{tabular}

We turn now to individual patterns according to the amount of input. In the definite condition, most children in the Spanish group favored the specific pattern whereas in the English group, half of the participants favored the specific pattern while the other half displayed the generic pattern (Table 4). In the balanced group, three out of seven children exhibited the specific pattern, while two children displayed the generic pattern and the remaining two children performed at chance level.

Table 4. Definite NPs: Individual subject patterns by amount of input.

\begin{tabular}{cccccccc}
\hline Groups & $\boldsymbol{N}$ & Generic & Pattern (\%) & Specific & Pattern (\%) & At Chance & Pattern (\%) \\
\hline Spanish & 9 & 3 & 33 & 6 & 67 & - & - \\
English & 6 & 3 & 50 & 3 & 50 & - & - \\
Balanced & 7 & 2 & 28 & 3 & 43 & 2 & 28 \\
\hline
\end{tabular}


For the bare plural NPs, both the English and the balanced group showed the same distribution: In both groups, most children showed the generic pattern. In contrast, in the Spanish group, most children favored the specific pattern (see Table 5). Thus, the English and the balanced groups were equally likely to favor the target interpretation (i.e., generic) in the bare NP context. However, the Spanish group was more prone to favor the specific pattern.

Table 5. Bare NPs: Individual subject patterns by amount of input.

\begin{tabular}{cccccccc}
\hline Groups & $\boldsymbol{N}$ & Generic & Pattern (\%) & Specific & Pattern (\%) & At Chance & Pattern (\%) \\
\hline Spanish & 9 & 4 & 44 & 5 & 55 & - & - \\
English & 6 & 4 & 67 & 2 & 33 & - & - \\
Balanced & 7 & 4 & 57 & 2 & 29 & 1 & 14 \\
\hline
\end{tabular}

To summarize, most children displayed the correct interpretation pattern: They showed the specific pattern in the definite condition and the generic pattern in the bare plural condition. When divided into age groups, the results indicated that the younger children have a tendency to opt for the specific pattern across conditions, as most of them showed the specific pattern in both the definite and the bare plural conditions. Similar to the younger children, the older children also favored one pattern across conditions, but in contrast to the former, the latter were more likely to display the generic pattern. Children also displayed different patterns according to the amount of input they received. The children in the Spanish group were more likely to exhibit the specific pattern in both types of NPs. Unlike the Spanish group, the English and the balanced groups did not seem to favor an interpretation across conditions. The children in the English group were more likely to show the generic pattern for the bare NPs, but they did not show a preferred pattern for the definite NPs. In the balanced group, most children displayed the appropriate pattern for each of the NPs (i.e., the specific pattern for the definite NPs and the generic pattern for the bare NPs).

\section{Discussion}

The purpose of our study was to investigate child L2 learners' interpretations of English definite and bare plural NPs. In particular, we focused on the effects of age and amount of input. We studied these two variables in relation to transfer and the children's developmental tendencies. Previous research on child L1 learners has shown that children tend to overextend the generic interpretation to specific contexts. In our study, we found that both English native speakers and child L2 learners incorrectly interpreted definite NPs as generic. However, overextension was greater by the L2 learners, and their performance significantly differed from that of native speakers. It could be argued that overextension of the generic meaning was greater in L2 children due to their age. L2 learners were younger $(4 ; 11-11 ; 7)$ than the native group $(8 ; 1-11)$. However, the child L2 learners who seemed to be more inclined towards the generic interpretation were those who were age-matched $(8 ; 4-11 ; 7)$ to the native group. Thus, we believe that these results suggest that another factor besides the children's natural predisposition towards the generic interpretation is affecting child L2 learners' interpretations of definite NPs. Child L2 learners' interpretation of English definite NPs appeared to be influenced by the L1 (e.g., Spanish). L2 children also have difficulties encoding the target interpretation of bare plurals. Learners' performance in the bare NP condition was almost at chance (55\% generics). This finding suggests that they still have not figured out that bare NPs have a generic interpretation. Nonetheless, it is important to note that the individual subject results showed that most children favored the specific pattern for the definite NPs and the generic pattern for the bare plural NPs. Therefore, although children have not yet acquired the target interpretation for both types of NPs, their interpretation preferences are moving in the right direction.

We had predicted that if child L2 acquisition mirrors bilingual acquisition and if cross-linguistic influence is unidirectional, children would not be influenced by their L1 (i.e., Spanish). This prediction was not supported by the results because children's interpretations were influenced by their L1 (e.g., 
greater overextension of the generic meaning to definite NPs). The role of transfer from the L1 to the L2 in the acquisition of NPs (e.g., English determiners) has been documented in previous studies examining adult L2 learners $[15,16,19,20]]$ as well as child L2 learners [21]. However, we argue that in contrast to adult L2 acquisition, there may be an interplay between the L1 and developmental patterns in child L2 acquisition. Due to their age, child L2 learners may display a predisposition for the generic meaning but like adult L2 learners they also seem to be transferring the semantic-form mapping of their L1 to that of the L2. Nonetheless, the effects of transfer might be lesser in child L2 learners than in adult L2 learners [1]. It could be argued that the acquisition of the NP is particularly problematic for learners because it is within the domain of the syntax-semantic/pragmatic interface. The acquisition of NPs requires morphological (e.g., determiners), semantic (e.g., generic and specific meaning) and pragmatic (e.g., speaker's point of view) cues. Some have claimed that linguistic structures whose distribution is constrained by the syntax-semantic/pragmatic interface are more prone to be affected by transfer, particularly if there is an overlapping between the languages [22-24]. The results from previous studies as well as the present study seem to support this claim.

The variable of age seems to not play a significant role in the learners' interpretation of English NPs. Performances of the two age groups were not significantly different. However, taking into consideration previous studies on L1 acquisition that have reported that younger children tend to overextend the generic interpretation more often than older children, results from the present study are unexpected. In this study, the older L2 learners were more prone to give a generic response than the younger L2 learners. We propose that these results may be related to the design of the task. In another study, we examined the interpretation of Spanish NPs by Spanish-speaking children [25]. We administered a Spanish version of the task to the very same group of children who participated in the present study, and we found that the preference for the generic interpretation in definite NPs was greater in the older children than in the younger ones. The design of the task may have favored the specific interpretation. In the present study, each question was accompanied by an image with specific referents (e.g., green lions) that had the characteristics to which the question alluded (e.g., $i$ Los leones son verdes? 'Are (the) lions green?'). For these reasons, we could argue that, similar to the study of Gelman and Raman [6], in our test, the specific interpretation was more salient than the generic one. The younger children might have been more influenced by the test bias than the older children.

If taking into consideration the amount of input that the children were receiving from Spanish and from English, it appears that amount of input has an effect on children's interpretation of English NPs. Overall, children with a similar amount of input in both languages were the most successful at interpreting English NPs. However, they were only more successful in correctly interpreting bare NPs and not definite NPs. Several studies have found that variations in the input play a role in the rate of acquisition of child L2 learners [26,27] and bilingual children [28-32]. Variation in the input can have an effect on the morphosyntactic domain as well as on the semantic domain [28]. The fact that the group with similar amounts of Spanish and of English input behaved more native-like than the group that is more frequently exposed to English rejects our hypothesis 2. One possible explanation for this could be that because the balanced group received similar amounts of input in English and Spanish, the children in this group are able to constantly compare the determiner systems of both languages. At a young age, children are able to identify what constructions are allowed in the language: Metalinguistic knowledge of NP interpretation is already established by the age of 6 years old [14]. We propose that children who receive similar amounts of input in the two languages become aware of the differences earlier, particularly in the forms where there is no overlapping between the languages (i.e., bare NPs). In forms that are present in both languages but that have different configurations (e.g., definite NPs), the amount of input will not be as relevant due to transfer effects. L2 learners may need more time to realize that correct interpretation in their L1 is incorrect in the L2. However, due to a small sample of participants, the number of analyzed responses for each group is limited and differences across groups were not statistically significant. Therefore, the results regarding the amount of input are suggestive rather than definitive. A larger sample size would be needed to validate these findings. 


\section{Conclusion}

We propose that interpretations of NPs by child L2 learners are affected by both developmental tendencies (i.e., generic default) and L1 transfer (i.e., extension of the generic meaning to definite NPs). Therefore, we believe that NP interpretation will be problematic to child L2 learners for a long period of time. Like L1 children, child L2 learners will have to overcome the child's natural predisposition of interpreting NPs as generic, which could persist even after the age of 8 . However, like L2 adults, child L2 learners also have to overcome L1 transfer effects. For example, they have to learn that English definite NPs can only hold a specific interpretation. Furthermore, they must also learn that argumentative bare plural NPs are allowed in English and that they have a generic meaning. We predicted that if child L2 acquisition resembles adult L2 acquisition, children would be more successful with bare NPs than with definite NPs. This hypothesis was partially confirmed by our results. Results showed that children receiving the same amount of input from Spanish and English outperformed the other children in only the correct interpretation of bare NPs. In other words, being exposed to Spanish and English for the same amount of time helps children correctly interpret bare plural NPs but not definite NPs. We argue that this may indicate that bare plural NPs are more easily acquired than definite NPs. Children become aware of the meaning of bare NPs more easily than they become aware of the target meaning of English definite NPs, which requires the child to unlearn the generic interpretation of definite plural NPs (L1 transfer).

All in all, child L2 learners need extensive input to learn target-like interpretation of English NPs. The data we presented in this study offer some insight into child L2 acquisition of NP interpretation. However, we acknowledge that a greater number of participants will be needed to confirm our findings, particularly those related to the amount of input. A future study should also test learners' linguistic proficiency in the L2 and examine whether it plays a role in their interpretations. In addition, we believe that a study that includes learners older than 11 years old (e.g., 15 years old) whose interpretations of NPs are no longer affected by the generic default would offer valuable information about how long transfer influences child L2 learners. A study such as the one proposed would offer an answer to the question of whether the effects of transfer recede by the time children overcome the generic default or whether the effects of transfer persist longer throughout the process of acquisition.

Acknowledgments: We would like to express our gratitude to the following persons: Silvina Montrul, Tania Ionin, Melissa Bowles and Andrei Cimpian for the collaboration in the creation of the task; and to the anonymous reviewers for their comments and suggestions. We are also thankful to the participants in PR and USA.

Author Contributions: A.M.-R. designed the online task, tested the English L2 learners, analyzed the data and collaborated in writing the manuscript. B.A.-R. tested the English native speakers, analyzed the data and collaborated in writing the manuscript.

Conflicts of Interest: The authors declare no conflict of interest.

\section{Appendix A}

Images and sentences used in the study

- $\quad$ Practice Trials

\begin{tabular}{ll}
\hline & Question \\
\hline & Do cats have hair? \\
\hline
\end{tabular}




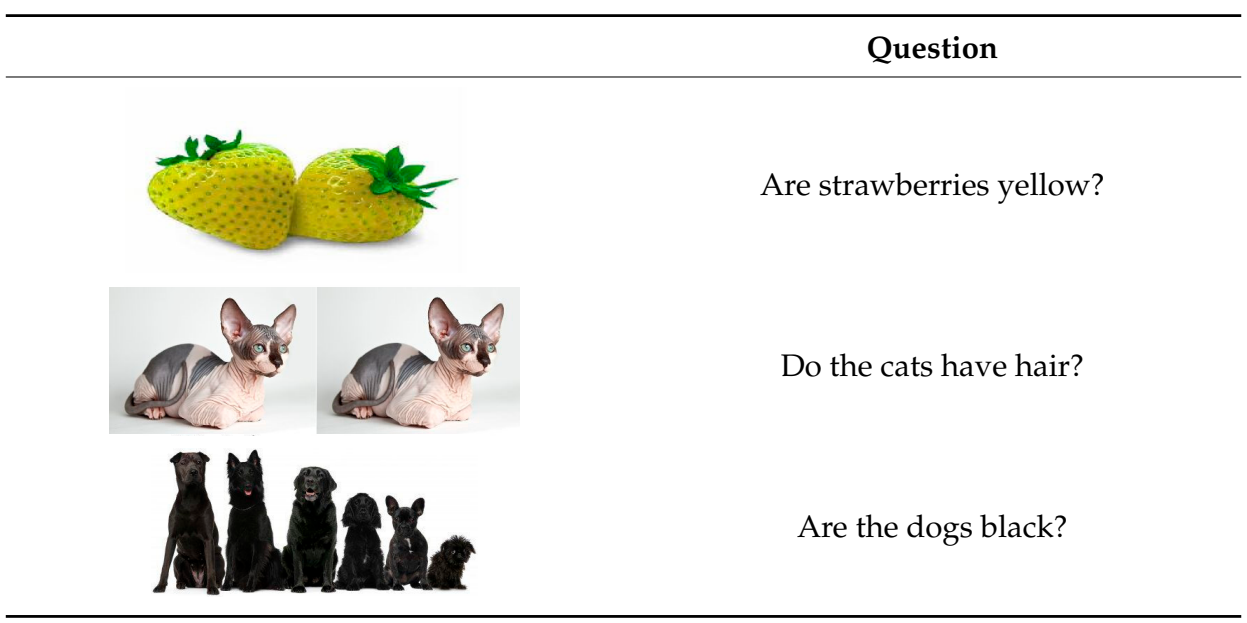

- Experimental items

Participants viewed each pair of pictures separately and listened to either the question with a bare NP or the question with a definitive NP associated with the picture. The bare and the definite plural conditions were not presented together. They were presented in two different sessions at different times.

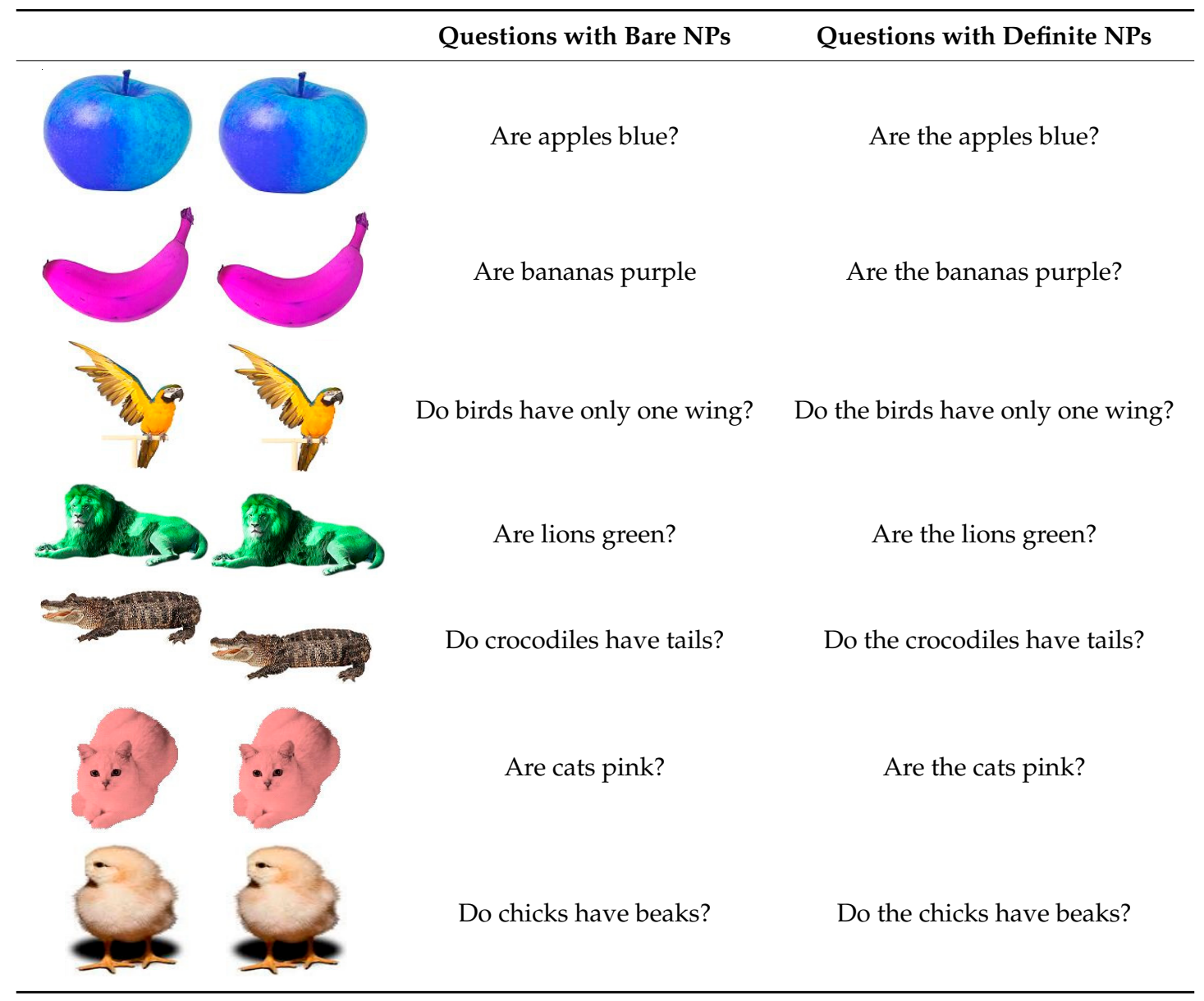




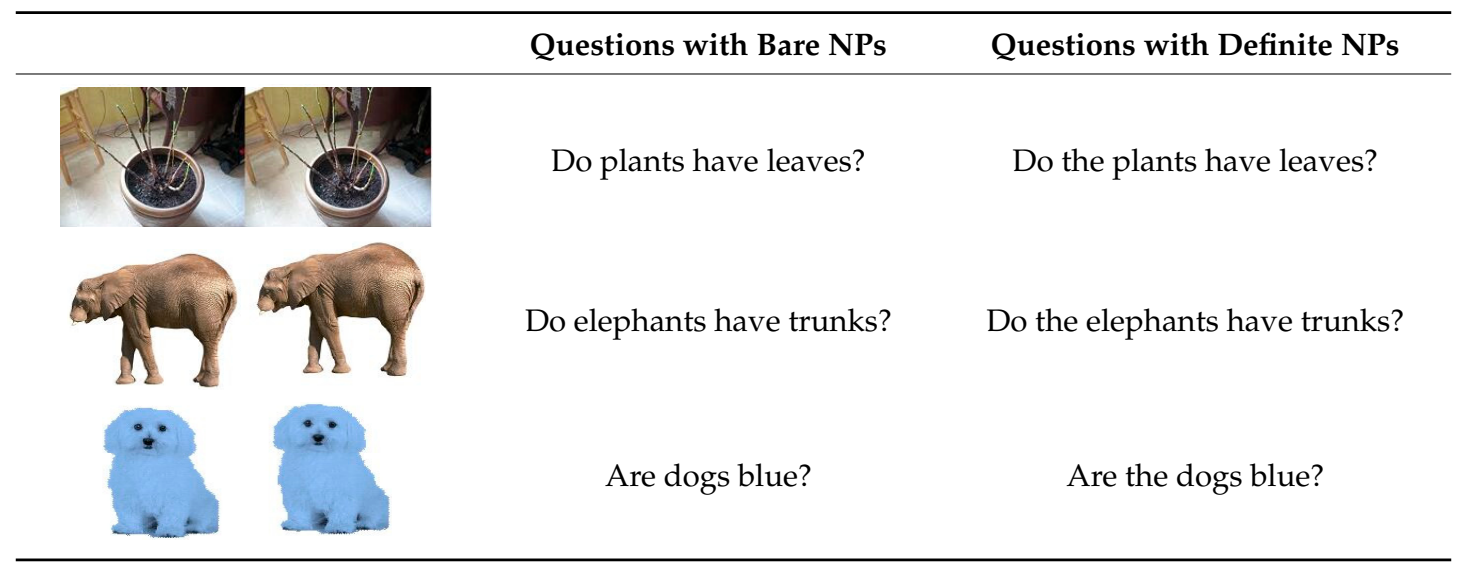

\section{References}

1. Kolb, N. Crosslinguistic Influence and Exposure Effects in Child Second Language Acquisition. In Proceedings of the 38th Annual Boston University Conference on Language Development (Online Supplement), Boston, MA, USA, 1-3 November 2013.

2. Snape, N.; Hirakawa, M.; Hirakawa, Y.; Hosoi, H.; Matthews, J. L2 English generics: Japanese child returnees' incomplete acquisition or attrition? In Selected Proceedings of the 2012 Second Language Research Forum, Pittsburgh, PA, USA, 18-21 October 2012; Miller, R.T., Martin, K.I., Eddington, C.M., Henery, A., Miguel, N.M., Tseng, A., Tuninetti, A., Walter, D., Eds.; Cascadilla Proceedings Project: Somerville, MA, USA, 2014; pp. 155-169.

3. Chierchia, G. Reference to kinds across languages. Nat. Lang. Semant. 1998, 6, 339-405. [CrossRef]

4. Gavarró, A.; Pérez-Leroux, A.; Roeper, T. Definite and bare noun contrasts in child Catalan. In The Acquisition of Syntax in Romance Languages, 1st ed.; Escobar, L., Torrens, V., Eds.; John Benjamins: Philadelphia, PA, USA, 2006; pp. 51-68, ISBN 9789027253019.

5. Cimpian, A.; Erickson, L.C. Remembering kinds: New evidence that categories are privileged in children's thinking. Cognit. Psychol. 2012, 64, 161-185. [CrossRef] [PubMed]

6. Gelman, S.A.; Raman, L. Preschool Children Use Linguistic Form Class and Pragmatic Cues to Interpret Generics. Child Dev. 2003, 74, 308-325. [CrossRef] [PubMed]

7. Gelman, S.; Sánchez Tapia, I.; Leslie, S.J. Memory for generic and quantified sentences in Spanish-speaking children and adults. J. Child Lang. 2015, 3, 1-14. [CrossRef] [PubMed]

8. Pérez-Leroux, A.T.; Munn, A.; Schmitt, C.; DeIrish, M. Learning definite determiners: Genericity and definiteness in English and Spanish. In Proceedings of the 28th Annual Boston University Conference on Language Development (Online Supplement), Boston, MA, USA, 31 October-2 November 2003.

9. Gelman, S.A. The Essential Child: Origins of Essentialism in Everyday Thought, 1st ed.; Oxford University Press: New York, NY, USA, 2003; ISBN 0195181980.

10. Leslie, S.-J. Generics: Cognition and acquisition. Philos. Rev. 2008, 117, 1-47. [CrossRef]

11. Roeper, T.; Strauss, U.; Zurer Pearson, B. The acquisition path of the determiner quantifier every: Two kinds of spreading. In Current Issues in First Language Acquisition: University of Massachusetts Occasional Papers in Linguistics, 1st ed.; Heizmann, T., Ed.; GLSA: Amherst, MA, USA, 2006; Volume 34, pp. 97-128, ISBN 1419650769.

12. Leslie, S.-J.; Gelman, S.A. Quantified statements are recalled as generics: Evidence from preschool children and adults. Cognit. Psychol. 2012, 64, 186-214. [CrossRef] [PubMed]

13. Meyer, M.; Gelman, S.A.; Stilwell, S.M. Generics are a cognitive default: Evidence from sentence processing. In Proceedings of the 33rd Annual Conference of the Cognitive Science Society, Boston, MA, USA, 20-23 July 2011; Carlson, L., Hoelscher, C., Shipley, T.F., Eds.; Curran Associates: Austin, TX, USA, 2011; pp. 913-918.

14. Serratrice, L.; Sorace, A.; Filiaci, F.; Baldo, M. Bilingual children's sensitivity to specificity and genericity: Evidence from metalinguistic awareness. Biling. Lang. Cognit. 2009, 12, 239-257. [CrossRef]

15. Ionin, T.; Montrul, S.; Crivos, M. A bidirectional study on the acquisition of plural noun phrase interpretation in English and Spanish. Appl. Psycholinguist. 2013, 34, 483-518. [CrossRef] 
16. Ionin, T.; Montrul, S. The role of L1 transfer in the interpretation with articles in plural definite in L2 English. Lang. Learn. 2010, 60, 877-925. [CrossRef]

17. Montrul, S.; Ionin, T. Dominant language transfer in Spanish heritage speakers and second language learners in the interpretation of definite articles. Mod. Lang. J. 2012, 96, 70-94. [CrossRef]

18. Marinis, T. Using on-line processing methods in language acquisition research. In Experimental Methods in Language Acquisition Research, 1st ed.; Blom, E., Unsworth, S., Eds.; John Benjamins Publishing Company: Philadelphia, PA, USA, 2010; pp. 139-162, ISBN 9789027219978.

19. Ionin, T.; Zubizarreta, M.L.; Bautista Maldonado, S. Sources of linguistic knowledge in the second language acquisition of English articles. Lingua 2008, 118, 554-576. [CrossRef]

20. Ionin, T.; Montrul, S.A.; Santos, H. Transfer in L2 and L3 acquisition of generic interpretation. In Proceedings of the 35th Annual Boston University Conference on Language Development, Boston, MA, USA, 5-7 November 2010; Danis, N., Mesh, K., Sung, H., Eds.; Cascadilla Proceedings Project: Somerville, MA, USA, 2011; Volume 1, pp. 283-295.

21. Morales-Reyes, A.; Gómez Soler, I. Transfer and semantic universals in the acquisition of the English article system by child L2 learners. Lang. Acquis. 2015, 23, 57-74. [CrossRef]

22. Hulk, A.; Müller, N. Bilingual first language acquisition at the interface between syntax and pragmatics. Biling. Lang. Cognit. 2000, 3, 227-244. [CrossRef]

23. Pérez-Leroux, A.T.; Lord, G.; O’Rourke, E.; Centeno-Cortés, B. Inalienable possession in L2 Spanish: The interface of syntax, morphology and the lexicon. In The Acquisition of Spanish Morphosyntax, 1st ed.; Pérez-Leroux, A.T., Liceras, J., Eds.; Kluwer: Dordrecht, The Netherlands, 2008; pp. 179-208, ISBN 978-94-010-0291-2.

24. Sorace, A.; Serratrice, L. Internal and external interfaces in the bilingual language development: Beyond structural overlap. Int. J. Biling. 2009, 13, 195-210. [CrossRef]

25. Morales-Reyes, A.; Arechabaleta, B.; Crespo, C. ¿Los Leones Son Verdes?: Interpretación de Los Determinantes en Niños Hispanohablantes. In Proceedings of the XVIII Congreso Internacional ALFAL, Bogotá, Colombia, 24-28 July 2017.

26. Blom, E.; Paradis, J.; Sorenson Duncan, T. Effects of input properties, vocabulary size, and L1 on the development of third person singulars in child L2 English. Lang. Learn. 2012, 62, 965-994. [CrossRef]

27. Paradis, J. Individual differences in child English second language acquisition: Comparing child-internal and child-external factors. Linguist. Approaches Biling. 2011, 1, 213-237. [CrossRef]

28. Bedore, L.M.; Peña, E.D.; Summers, C.L.; Boerger, K.M.; Resendiz, M.D.; Greene, K.; Bohman, T.M.; Gillam, R.B. The measure matters: Language dominance profiles across measures in Spanish-English bilingual children. Biling. Lang. Cognit. 2012, 15, 616-629. [CrossRef] [PubMed]

29. Montrul, S.; Potowski, K. Command of gender agreement in school-age Spanish bilingual children. Int. J. Biling. 2007, 11, 301-328. [CrossRef]

30. Nicoladis, E.; Palmer, A.; Marentette, P. The role of type and token frequency in using past tense morphemes correctly. Dev. Sci. 2007, 10, 237-254. [CrossRef] [PubMed]

31. Thomas, E.M.; Williams, N.; Jones, L.A.; Davies, S.; Binks, H. Acquiring complex structures under minority language conditions: Bilingual acquisition of plural morphology in welsh. Biling. Lang. Cognit. 2014, 17, 478-494. [CrossRef]

32. Unsworth, S. Assessing the role of current and cumulative exposure in simultaneous bilingual acquisition: The case of Dutch gender. Biling. Lang. Cognit. 2013, 16, 86-110. [CrossRef]

(C) 2017 by the authors. Licensee MDPI, Basel, Switzerland. This article is an open access article distributed under the terms and conditions of the Creative Commons Attribution (CC BY) license (http://creativecommons.org/licenses/by/4.0/). 